risk added in doing so, but the surgeon should be prepared to advise the patient to accept the added risk in view of avoiding prolonged incapacitation from work.

Mr. R. H. Anglin Whitelocke (Oxford) said that one point he thought of the greatest importance was that in oblique fractures of the tibia portions of muscle and fascia often became interpolated between the ends of the bone. Unless this was removed, satisfactory union would not follow. In such cases he urged the necessity of the open method of treatment and suturing the ends together. The dangers of the open method were not great with ordinary surgical care.

Mr. ALFRED SHEEN thought that fixation in plaster of paris soon after the injury was the best method of obtaining a satisfactory result; he kept patients with fractures of the tibia in hospital only a few days and had never found any disadvantage in the practice.

Mr. JoRdAN Lloyd agreed with Mr. Murray that the interests of abdominal and other major surgery were liable at the present time to draw attention away from such conditions as simple fractures, and he would not be surprised to learn that the results of the treatment of fractures were worse now than some years ago.

Mr. Murray, in reply, explained further the advantages he claimed for the splint which he used, and pointed out that it allowed some rotation outwards of the lower fragment which brought it into line with the upper when the limb was in the position of rest; the knee-joint could be easily controlled if necessary. He agreed that a considerable proportion of oblique fractures of the tibia were best treated by open operation, and he had submitted many of his cases to this treatment during the last few years.

(I'o be continued.)

\section{ON THE PROTECTIVE EFFECT ACHIEVED BY ANTITYPHOID INOCULATION AS EXHIBITED IN TWO NEW STATISTICAL REPORTS.}

By A. E. WRIGHT, M.D.,

Late Professor of Pathology, Army Medical School. Netley; Pathologist, St. Mary's Hospital, Paddington, W.

Is the Lancet of September 6th, 1902, I gathered together and set forth in a synoptical table all the statistics which were available up to that date with regard to the effect of antityphoid inoculation. In a special supplement appended to the same issue I marshalled the materials for the critical estimation of the value of each of the statistics. I have recently, through the kindness of Sir William Taylor, K.C.B., Director-General of the Army Medical Service, obtained permission to publish two further statistical reports which have been received at the War Office during the last twelve months.

The first statistical report deals with the inçidence of typhoid fever and the death-rate from the disease in inoculated and uninoculated soldiers in India during the year Igor. The second deals with the incidence of typhoid fever in the inoculated and uninoculated in Lord Methuen's column at the Modder River, South Africa, from December, 1899, to March, 1900.

TABLE I.-Showing the Incidence of and Death-rate from Typhoid Fever in the British Army in India during the Year 1901.

\begin{tabular}{|c|c|c|c|c|c|}
\hline . & $\begin{array}{c}\text { Average } \\
\text { Strength } \\
\text { during the } \\
\text { Year. }\end{array}$ & $\begin{array}{l}\text { Cases of } \\
\text { Typhoid } \\
\text { Fever. }\end{array}$ & $\begin{array}{l}\text { Deaths } \\
\text { from } \\
\text { Typhoid } \\
\text { Fever. }\end{array}$ & $\begin{array}{l}\text { Incidence- } \\
\text { rate. }\end{array}$ & $\begin{array}{l}\text { Death- } \\
\text { rate. }\end{array}$ \\
\hline $\begin{array}{l}\text { Uninoculated. } \\
\text { Inoculated...... }\end{array}$ & $\begin{array}{r}.55 .955 \\
4,883\end{array}$ & $\begin{array}{r}744 \\
32\end{array}$ & $\begin{array}{r}\mathbf{1 9 9} \\
3\end{array}$ & $\begin{array}{c}\text { Per Cent. } \\
\mathbf{1 . 3 3} \\
0.66\end{array}$ & $\begin{array}{c}\text { Per Cent. } \\
0.36 \\
0.06\end{array}$ \\
\hline
\end{tabular}

We learn from this table that antityphoid inoculation diminished the incidence-rate of typhoid fever by one-half and the death-rate by five-sixths.

A further point of interest in the table is its testimony to the duration of the protection afforded by antityphoid inoculation. It may be premised in this connexion that the number of inoculated in the table above represents a falling off of 1,100 from the figure of the previous year-a falling off due to the practioal suspension of antityphoid inoculations. It follows that the statistics here in question refer almost exclusively to men inoculated in 1898, 1899, and 1900. So far as they apply to men inoculated in 1900 , they confirm the statistics of that year, which showed that the protection conferred by inoculation in 1899 showed no signs of diminishing in 1900. So far as the statistics of 1901 refer to a residue of the 4,000 men inoculated by myself in India in 1898-9 they amplify previous statistics to the extent that they suggest that the protective effect of inoculation continues for a minimum of three years.

The second statistical record applies, as already mentioned, to Lord Methuen's column during a limited period of the South African war. It was furnished by Surgeon-General Townsend, C.B.

TABLE II.-Showing the Incidence of Typhoid Fever in Lord Methuen's Column at the Modder River, South Africa, from December, 1899, to March, 1900.

\begin{tabular}{|c|c|c|c|c|}
\hline & & Number. & $\begin{array}{c}\text { Cases of } \\
\text { Typhoid Fever. }\end{array}$ & $\begin{array}{l}\text { Incidence- } \\
\text { rate. }\end{array}$ \\
\hline $\begin{array}{l}\text { Uninoculated .. } \\
\text { Inoculated }\end{array}$ & $\begin{array}{ll}\cdots & \ldots \\
\cdots & \cdots\end{array}$ & $\begin{array}{r}\text { ro, } 981 \\
2,535\end{array}$ & $\begin{array}{r}257 \\
26\end{array}$ & $\begin{array}{c}\text { Per Cent. } \\
2.3 \\
\text { 1.0 }\end{array}$ \\
\hline
\end{tabular}

It will be noted that the table testifies to a diminution of the incidence-rate by more than half during the period of observation. It would seem legitimate, in view of statistics set forth above and of previous statistics, to infer the continuance of a similarly diminished rate of incidence during the whole of these men's service in South Africa. It will be noted also that this table discloses nothing with regard to the case-mortality of the inoculated and uninoculated attacked by typhoid fever. This omission is, no doubt, due to the fact that the sick were transferred to hospitals at the base, and passed out of Surgeon-General Townsend's ken We may probably, in view of statistics in Table I supra, and of those included in my synoptical table infer that there was here superadded to the diminution in the incidence-rate of typhoid also a diminution in the death-rate.

\section{REVIEWS,}

THERAPEUTICS.

TEN years have elapsed since the first edition of Dr. HARE' System of Practical Therapeutics was published." In our review of that work (BRITISH MEdical Journal, i892) we took occasion to point out that while it formed a satisfactory guide to modern treatment in general, it might yet have attained greater usefulness by still closer regard to details. The work now appears in three substantial volumes, each comprising close on 900 pages, and a vast number of subjects are treated by many writers, with a fullness of detail that should satisfy the largest clinical appetite. All the earlier articles have been revised, and nearly half of the total have been written afresh or are entirely new. In the first volume, the broader lines of therapy are considered, opened by an article by Dr. Horatio C. Wood on general therapeutic considerations, marked by strong common sense. Dr. Remington deals with prescription-writing in an article which deserves careful study in the interest of the dispensing chemist no less than in that of the patient. In discussing general sanitation, Dr. Baker advocates strong legislative measures somewhat ahead of the present state of public opinion. $\mathrm{He}$ would prevent all preventable diseases by local authority, but, as he himself admits, public opinion is as yet hardly educated up to the point of acceptance of wholesale restraint. Dr. Burney Yeo, one of the few English contributors, writes of nutrition and foods, and the subject of general exercise is discussed by Dr. Hartwell in an article interesting from the physiological point of view, though it does not throw much light on the uses of exercise as means of treatment in disease. Articles by Dr. Mitchell on rest cure and by Dr. Rockwell on electro-therapeutics will not strike the English reader as being in any way in advance of familiar home textbooks. The uses of the $x$ rays are hardly mentioned, while the light treatment of skin affections obtains no mention either in this place or in the article in the next volume on the treatment of skin diseases. Hydrotherapy, climate, and mineral waters are next dealt with, the information on the two latter sub-

1 A System of Practical Therapeutics. Edited by Hobart Amory Hare. M.D. Second edition, three vols. London: Williams and Norgate, 